\title{
Os principais canais de transferência internacional de tecnologia em diferentes paradigmas tecnológicos: implicações para a superação do subdesenvolvimento *
}

\author{
Tulio Chiarini ${ }^{* *}$ \\ Ana Lúcia Gonçalves da Silva ***
}

\begin{abstract}
Resumo
Apesar do reconhecimento que a superação do atraso tecnológico ocorre mediante a construção de aptidões tecnológicas domésticas, a transferência internacional de tecnologia mostrou-se relevante em diferentes momentos históricos e em diferentes nações em processo de emparelhamento. Com a evolução tecnológica em cada paradigma, diversos canais de transferência internacional de tecnologia foram mais ou menos efetivos. A partir de uma análise histórica, busca-se apresentar que os principais canais de transferência foram mudando com o tempo para responder às mudanças tecnológicas. Portanto, um canal protagonista em certo momento histórico passa a ser coadjuvante em outros, pois a tecnologia dominante apresenta características que requerem canais específicos para que seja transferida.
\end{abstract}

Palavras-chave: Transferência internacional de tecnologia; Paradigma tecnológico; Catch-up tecnológico; Subdesenvolvimento.

\begin{abstract}
The main channels of international technology transfer in different technological paradigms: implications to overcome underdevelopment

The main international technology transfer channels in different technological paradigms: implications for overcoming underdevelopment. Despite the recognition that overcoming technological backwardness occurs through the construction of domestic technological capabilities, the international transfer of technology has proved to be a relevant strategy at different moments in history and for different nations during their catching-up processes. With the technological evolution in each paradigm, several international technology transfer channels were relatively effective. Based on a historical analysis, we try to show that the main channels have changed over time to respond to technological changes. Therefore, a protagonist channel in one historical moment happens to play a supporting role in others, given that the dominant technology presents characteristics that require the transfer of specific channels.
\end{abstract}

Keywords: International technology transfer; Technological paradigm; Technological catch-up; Underdevelopment.

JEL O10, O30, O33.

\footnotetext{
* Artigo recebido em 11 de agosto de 2015 e aprovado em 24 de setembro de 2017. Os pensamentos e ideias expressos neste trabalho não refletem necessariamente aqueles das instituições as quais os autores estão vinculados. Os autores gostariam de agradecer os pareceristas anônimos da Revista Economia \& Sociedade pelos comentários e contribuições. Os eventuais erros e omissões são de inteira responsabilidade dos autores. Os autores gostariam ainda de agradecer o apoio da Coordenação de Aperfeiçoamento de Pessoal de Nível Superior (Capes) [Processo: BEX 5796/15-6].

${ }^{* *}$ Analista em C\&T do Instituto Nacional de Tecnologia (INT) do Ministério da Ciência, Tecnologia, Inovações e Comunicações (MCTIC) e Instituto di Ricerche sulla Popolazione e le Politiche Sociali (IRPPS) do Consiglio Nazionale delle Ricerche (CNR), Rio de Janeiro, RJ, Brasil. E-mail: tulio.chiarini@int.gov.br.

${ }^{* * *}$ Professora do Instituto de Economia (IE) da Universidade Estadual de Campinas (Unicamp), Campinas, SP, Brasil. E-mail: algsilva@unicamp.br.
} 


\section{Introdução}

A transferência internacional de tecnologia (subsequentemente abreviada por TIT) possibilitou o emparelhamento tecnológico entre nações. De maneira relativamente mais rápida e menos custosa, tecnologias (e conhecimentos) produzidas além das fronteiras nacionais foram implementadas no processo produtivo interno e permitiram às nações retardatárias se beneficiarem do uso de técnicas de alta produtividade.

A historiografia mostra exemplos de nações que utilizaram, de forma bemsucedida, tecnologias desenvolvidas alhures para desenvolverem seu aparato produtivo, utilizando diferentes canais para se apropriarem das melhores tecnologias (e conhecimentos) disponíveis. Foi o caso, por exemplo, da França e da Bélgica (Harris, 1998; Rosenberg, 2006 [1982]), dos Estados Unidos (Andreas, 2013; Freeman; Soete, 2008 [1974]; Jeremy, 1981; Nelson; Wright, 1992), dos países escandinavos - Suécia, Dinamarca e Noruega - (Bruland, 1998; Harris, 1998), da Finlândia (Myllyntaus, 1990), do Japão (Cooper, 1972; Hall, 1984; Ozawa, 1985) e, mais recentemente, da Coréia do Sul (Kim, 1999, 2005 [1997]; Pack, 2005; Viotti, 2002).

A partir da análise caso a caso de diferentes nações em diferentes momentos históricos, é possível responder a algumas perguntas: os principais canais de TIT se mantiveram no tempo ou são específicos a cada momento histórico? Como os exemplos históricos podem ajudar a identificar os principais canais de transferência de tecnologia? A partir dessas respostas é possível verificar a proposição deste trabalho: as características relacionadas tanto à própria tecnologia quanto às particularidades de cada nação são essenciais para o entendimento de como a TIT se deu ao longo do tempo. Em última instância, o que se busca é mostrar que os principais canais de TIT foram mudando com o tempo para responder às mudanças tecnológicas. Portanto, um canal que era bastante utilizado em dado momento histórico deixa de ser, pois a tecnologia dominante passa a apresentar certas características que requerem canais específicos para que ela seja transferida.

Para fins de validar a preposição lançada anteriormente, este artigo é estruturado da seguinte maneira: na seção 1, apresenta-se a delimitação teórica do objeto de análise, isto é, a tecnologia. Portanto, nesta seção é apresentado um conceito de tecnologia que pode ser utilizado em diferentes momentos históricos com o intuito de verificar como os canais para transferir a tecnologia foram se modificando com o tempo. Além disso, há espaço nessa seção para se discutir o conceito de transferência de tecnologia. Na seção 2, apresentam-se alguns elementos da tecnologia dominante na Primeira Revolução Industrial que ajudam a caracterizar os principais canais de transferência de tecnologia à época. Na seção 3 , são apresentadas as diferenças nas tecnologias dominantes no Paradigma da 
Produção em Massa (Fordista) enquanto que na seção subsequente o foco está nas mudanças tecnológicas do Paradigma das Tecnologias da Informação e Comunicação (TICs), sempre com o intuito de verificar como tais mudanças afetam os principais canais de TIT.

Nesse momento cabe uma explicação quanto ao recorte metodológico: optou-se por utilizar a proposição analítica de 'três paradigmas' apresentados por Tigre (2005) ao invés das 'cinco revoluções tecnológicas' teorizadas por Perez (2002, 2009). Não foram encontradas diferenças históricas marcantes no que concerne à TIT que justificasse a separação analítica em muitos períodos o que dificultaria encontrar elementos que diferenciassem um período do outro. Finalmente, vale mencionar que a decisão por ancorar a análise a partir das principais mudanças tecnológicas decorre do seu entendimento como um processo disruptivo, com possíveis mudanças de direção e transformações estruturais, contrariando o entendimento do desenvolvimento como um processo cumulativo unidirecional em um caminho prefixado.

Para concluir este estudo, aprecia-se a TIT e a superação do atraso e como as características das tecnologias dominantes no atual Paradigma das TICs colocam elementos de dificuldade para a TIT. Finalmente são apresentadas algumas considerações retomando os principais pontos destacados no decorrer do estudo.

\section{Da tecnologia}

Existem diferentes conceitos de tecnologia disponíveis na literatura. Por exemplo, de acordo com Arthur (2011), a tecnologia possui três dimensões:

The first and most basic one is that technology is a means to fulfill a human purpose. (...) As a means, a technology may be a method or process or device (...). The second definition (...) is a plural one: technology as an assemblage of practices and components (...). [The third meaning] is: technology as the entire collection of devices and engineering practices available to a culture (op. cit., p. 28).

Já para Sabato (1979),

llamaremos tecnología al conjunto ordenado de los conocimientos empleados en la producción y comercialización de bienes y servicios, y que está integrado no sólo por conocimientos científicos - provenientes de las ciencias naturales, sociales y humanas, etc. - sino también por conocimientos empíricos que resultan de observaciones, experiencias, aptitudes específicas, tradición (oral y escrita), etc. (op. cit., p. 60).

Quesito no qual os conceitos apresentados anteriormente são complementares e entendem a tecnologia como um 'artefato' (máquinas, 
computadores, motores, etc.) e conhecimento (codificado e tácito) com um propósito (ou vários). Assim, tecnologia pode ser um conjunto sistêmico e ordenado de informações (ou seja, conhecimentos codificados e/ou tácitos) para a manufatura de produtos, aplicação de um processo e realização de serviços (sendo esses os propósitos). Esse conjunto sistêmico de informações abrange o conhecimento técnico-científico - no qual o produto final é baseado -, a capacidade organizacional para converter os insumos produtivos relevantes em itens ou serviços acabados e os conhecimentos empíricos.

Assim, máquinas, computadores, motores, etc. (tecnologias entendidas como 'artefatos') podem ser disseminados de uma nação à outra. Igualmente, o conhecimento (codificado e tácito) também pode ser dissipado de uma nação à outra. Desse modo, a TIT é o processo pelo qual uma tecnologia (artefatos ou conhecimentos codificados/tácitos) é disseminada de uma nação à outra por diferentes canais. De acordo com a Unctad (2001), a TIT “(...) takes the form of a technology transfer transaction (...) which involves the communication, by the transferor, of the relevant knowledge to the recipient" (op. cit., p. 14).

A TIT pode se dar por canais legais, mas também por canais ilegais (como contrabando, roubo, espionagem) sendo que os principais canais utilizados mudaram no decorrer do tempo e a proposição aqui levantada é que eles são condicionados às características das tecnologias dominantes em diferentes momentos históricos. É impensável, por exemplo, no início da Primeira Revolução Industrial, aceitar exclusivamente o comércio de máquinas como canal exclusivo de TIT, uma vez que as máquinas (ou melhor, as máquinas-ferramenta mecânicas ${ }^{1}$ ) ainda eram rudimentares, pouco precisas, não padronizadas e passavam por aperfeiçoamentos incrementais constantemente (Landes, 2005). A contratação de mão de obra mostrou-se mais efetiva na época, uma vez que o conhecimento tecnológico estava basicamente nela corporificado. Com a migração, os trabalhadores levavam consigo know-how e ajudavam a difundir o

(1) De acordo com Marx (1985 [1890]), toda maquinaria desenvolvida consiste de três partes, a saber: motor, transmissão e máquina-ferramenta. O motor é a força motriz de todo o mecanismo, a transmissão é constituída de volantes, eixos, rodas dentadas, turbinas, barras, cabos etc. e regula o movimento. Ambos existem para transmitir movimento à máquina-ferramenta a qual inaugura a Revolução Industrial no século XVIII. “A máquina-ferramenta é portanto um mecanismo que, ao lhe ser transmitido o movimento apropriado, realiza com suas ferramentas as mesmas operações que eram antes realizadas pelo trabalhador com ferramentas semelhantes. (...) Quando o homem passa a atuar apenas como força motriz numa máquina-ferramenta, em vez de atuar com a ferramenta sobre o objeto de trabalho, podem tomar seu lugar o vento, a água, o vapor etc., e torna-se acidental o emprego da força muscular humana como força motriz. Essas mudanças dão origem a grandes modificações técnicas no mecanismo primitivamente construído apenas para ser impulsionado pela força humana. (...) Depois que os instrumentos se transformam de ferramentas manuais em ferramentas incorporadas a um aparelho mecânico, a máquina motriz, o motor, adquire uma forma independente, inteiramente livre dos limites da força humana. Com isso, a máquina-ferramenta (...) se reduz a um simples elemento da produção mecanizada" (Marx, 1985 [1890], p. 427-431). 
conhecimento. Em diferentes épocas outras formas de TIT surgiram, conforme é apresentado nas seções que se seguem.

\section{A TIT na revolução industrial originária}

A TIT não é um fenômeno novo, no entanto, sua escala e intensidade se aceleraram a partir da Revolução Industrial Inglesa, quando as tecnologias desenvolvidas na Inglaterra forneceram maior potencial para o crescimento da produtividade em relação às tecnologias tradicionais (Chang, 2009) e possibilitaram as bases para o desenvolvimento industrial inglês e de demais nações (da Europa Ocidental, sobretudo França, Bélgica, Prússia) ${ }^{2}$.

À época, o conhecimento técnico-prático pertencia exclusivamente aos trabalhadores, os quais se apropriavam diretamente do conhecimento envolvido na definição do processo produtivo (Tigre, 2005). As habilidades detidas pelos trabalhadores eram essenciais para o desenvolvimento industrial não só inglês, mas também da Europa continental que já passava por um processo de industrialização, mesmo que ainda incipientemente.

Portanto, a tecnologia possuía um caráter estritamente exógeno - isto é, incorporada nos trabalhadores e nas máquinas-ferramenta mecânicas - (Tigre, 2005) em um ambiente de mudança tecnológica lenta. Essa era muito irregular, sendo que as mais importantes invenções tinham um impacto inicial muito modesto e as contribuições da ciência e educação formal eram módicas ${ }^{3}$ (Crafts, 1998).

Dado o caráter da tecnologia nos primórdios da Revolução Industrial Inglesa, os movimentos de tecnologia entre a Grã-Bretanha e o continente Europeu

(2) "As tecnologias britânicas forneceram as bases para o desenvolvimento industrial, primeiro da Europa Ocidental, em seguida dos Estados Unidos e, mais tarde, de outros países selecionados nos quais as condições se mostraram favoráveis. A mão de obra qualificada britânica, seu espírito empreendedor e, algumas vezes, os capitais daquele país exerceram um papel crítico durante esses estágios iniciais, ao levar para a Europa Ocidental as novas tecnologias têxteis, de transporte, de energia e de engenharia. Os recebedores da tecnologia britânica encontravam-se, portanto, em uma situação nitidamente favorável. Eles puderam industrializar-se por meio da simples transferência de tecnologias já existentes, sem precisar reinventá-las "(Rosenberg, 2006, p. 366).

(3) "Their full effects only materialized as the potential of the technologies was explored, often by learning through the experience of using them, and as they became cheaper and more widely diffused" (Crafts, 1998, p. 197). Teoricamente falando, o processo de evolução de uma tecnologia requer melhorias incrementais as quais, com o tempo, reduzem os custos de produção dessa tecnologia (no caso, uma máquina) e aumentam a qualidade, o desempenho e a confiabilidade (Freeman; Soete, 2008 [1974]; Perez; Soete, 1988). Assim, na Primeira Revolução Industrial, as máquinas ainda se encontravam no período da primeira introdução, período de aprendizado, e com o tempo os processos de produção foram sendo padronizados e as máquinas tornaram-se 'maduras'. 
no século XVIII ocorreram basicamente pelo fluxo de trabalhadores qualificados ${ }^{4}$. Isto visto que novas técnicas foram desenvolvidas empiricamente e que, uma vez desenvolvidas, tornaram-se parte da prática convencional. Esta foi transmitida a outras nações por meio de treinamento no local de trabalho (training on-the-job), principalmente via aprendizagem formal ou informal. (Harris, 1991; Landes, 2005).

A transferência de trabalhadores se fazia necessária, pois, neste período de consolidação da produção industrial, eles eram responsáveis pela definição do processo produtivo, sendo encarregados de estabelecer o fluxo e as rotinas de trabalho, contratando aprendizes, os quais eram por eles treinados. Eram portadores de habilidades (person-embodied skills ou human-embodied technologies). O conhecimento tecnológico (da época) pertencia ao trabalhador, i.e., era apropriado por ele, assim, sua transferência para outras nações resultava em transferência direta de tecnologia. Tal conhecimento também se corporifica no capital (máquinas, capital embodied) e sua aquisição era igualmente importante, embora fosse dificultada pelas suas dimensões e pela dificuldade de transportá-las de uma região (como Manchester na Inglaterra) a regiões no interior da Europa continental.

A TIT entre a Grã-Bretanha e a Europa Continental (França, Bélgica, Prússia), durante o período da Primeira Revolução Industrial, ocorreu de modo relativamente moroso e com algumas dificuldades (Landes, 2005). Primeiro, as máquinas-ferramenta mecânicas, ainda em estágio de aprimoramentos, passavam por mudanças incrementais intensas e frequentes; segundo, o conhecimento tecnológico era extremamente tácito em sua natureza e, portanto, dependente dos trabalhadores (Harris, 1998); terceiro, o ambiente de mudança tecnológica era bastante 'arrastado'; e finalmente, quarto, havia proibição (legal) da emigração de artesãos britânicos até 1825 e da transferência de equipamentos e das grandes invenções têxteis da Grã-Bretanha aos demais países até 1842 (Jeremy, 1977).

$\mathrm{O}$ incentivo à mobilidade de trabalhadores, à espionagem e ao contrabando ocorria uma vez que a natureza prática (empírica) da tecnologia na época tornava particularmente difícil a transferência por meios escritos e documentados, ainda mais quando a ciência tinha impacto minoritário na indústria ${ }^{5}$, portanto, o

(4) "We know that much British technology was transferred to France [and other European countries] by the most effective means, that of moving skilled workers, but it is certain that counter-measures, legal and managerial, slowed down the process, as did the wars" (Harris, 1991, p. 23). "The preponderant method of acquiring British technology was the obtaining of skilled British workers, and intense efforts were put into this; written descriptions and drawings of equipment and machinery were acknowledged to be of little use" (Harris, 1991, p. 26).

(5) Os escritos de estudiosos e 'cientistas' tiveram um papel pequeno como canal de TIT nesta fase do capitalismo (Harris, 1991), pois os princípios científicos, por detrás das operações industriais, eram ainda pouco compreendidos, o que impossibilitava a documentação em termos universais (Chang, 2009). 
conhecimento era adquirido por meio de experiências como a observação, a imitação e a prática, por métodos (raramente) permitidos ou (frequentemente) ilegais (como a espionagem ${ }^{6}$ ).

Com a crescente especialização e sofisticação das máquinas-ferramenta mecânicas, habilidades específicas e cumulativas foram se tornando cada vez mais importantes (Freeman; Soete, 2008 [1974]), assim, a sua importação requeria também um treinamento para operá-la. Por isso, era comum que máquinasferramenta mecânicas e seus operadores fossem adquiridos conjuntamente.

Enquanto que, no século XVIII, a transferência das habilidades homem a homem no local de trabalho (especialmente dos imigrantes britânicos que treinaram uma geração de trabalhadores especializados) e a espionagem (Landes, 2005) eram os principais canais de TIT, em outros momentos históricos diferentes canais mostraram-se igualmente eficientes.

Em meados do século XVIII e início do XIX, as máquinas-ferramenta mecânicas e instrumentos tornaram-se mais complexos e passaram a ter cada vez mais tecnologias incorporadas e alguns fabricantes de máquinas já operavam com modelos padronizados, sendo possível a venda a partir de descrições em catálogos ${ }^{7}$ (Landes, 2005). Neste contexto, a sua importação passou a ser um canal tão significativo de TIT quanto à contratação de trabalhadores (Chang, 2009). Ademais, à medida que métodos científicos foram sendo utilizados para codificar e explicar o funcionamento das máquinas, outros canais passaram a ser significantes para a TIT $^{8}$.

A importação de máquinas como canal de TIT torna-se de fato relevante quando os ingleses desenvolvem novas indústrias que significantemente mudam o caráter e o ritmo da TIT. Trata-se da indústria focada no desenvolvimento de máquinas (bens de capital). O lucro dos produtores de bens de capital vinha exatamente da difusão da tecnologia e isto implicou uma transição do processo de

(6) A espionagem era central na transferência de tecnologia da Grã-Bretanha para a França, para os países da Escandinávia e também para Áustria, Rússia e demais países (Harris, 1998).

(7) “As ferramentas tornaram-se mais pesadas e mais rígidas (...), mais automáticas e precisas (...) e mais versáteis e fáceis de operar (...). Em meados do século XIX, a maioria das máquinas-ferramenta mecânicas atualmente usadas (...) já tinha sido criada (...) e fabricantes de equipamentos já mantinham estoques de modelos padronizados e vendiam a partir de descrições em catálogos" (Landes, 2005, p. 101). Ao passo que as máquinas foram sendo aperfeiçoadas, com a transição para um novo tipo de construção mecânica (com o surgimento das peças intercambiáveis, i.e., partes precisas que se encaixam e se integram com outras em um equipamento maior), houve a possibilidade de uniformização e padronização de sua fabricação, permitindo a transferência de máquinas em maior escala (Landes, 2005).

(8) Assim, conforme o conhecimento desincorporado foi aumentando, tornou-se importante proteger as ideias (os ativos intangíveis) ao invés de trabalhadores ou máquina, para a manutenção e fortalecimento das vantagens competitivas. As leis inglesas que proibiam a saída de trabalhadores e as exportações de máquinas tiveram sua eficácia reduzida e acabaram sendo revogadas. Em seu lugar, foram criados meios de proteger as ideias, como o surgimento de patentes, por exemplo (Chang, 2009). 
industrialização como um todo (Bruland, 1998). Esta transição teve implicações para a difusão da industrialização, para a venda de equipamentos e para a difusão das habilidades necessárias para a produção industrial, o que afetou sobremaneira a TIT (Bruland, 1998).

A TIT foi menos dinâmica até a Revolução dos Transportes $^{9}$ e das Comunicações, as quais a tornaram relativamente mais facilitada. As melhorias nos transportes e nas comunicações foram os principais facilitadores tecnológicos para o crescente fluxo de conhecimentos tecnológicos, assim como de bens de capital através das fronteiras nacionais (Mowery; Rosenberg, 2005 [1998]).

\section{A TIT no paradigma da produção em massa}

A tecnologia sofre algumas mudanças significativas: torna-se mais complexa e contínua e cada vez mais a ciência passa a ter papel influenciando-a (Mowery; Rosenberg, 2005 [1998]), diferentemente da Primeira Revolução, que fora bastante arcaica e teve papel secundário da ciência e, sem dúvidas, seus maiores trunfos tecnológicos foram à estrada de ferro e o barco a vapor (précientíficos) (Hobsbawn, 1978). As duas mais importantes contribuições à tecnologia decorrem da eletricidade e da química. Outras mudanças igualmente ajudam a entender as diferenças tecnológicas: a expansão sistemática do sistema fabril e a organização da produção em massa, a descoberta de que o maior mercado potencial estava nos rendimentos crescentes da classe trabalhadora e o aumento na escala da empresa econômica e a concentração da produção e da propriedade (Hobsbawn, 1978).

A essência das novas tecnologias está, portanto, na busca do conhecimento exato, no planejamento de processos: desde a minúcia de operações manuais (com base nos 'estudos de tempos e movimentos') até o lay-out de máquinas de fábricas gigantescas (Jevons, 1931). Embora nem todo tipo de tecnologia derive da pesquisa científica e nem todos os resultados da pesquisa se transformem em tecnologia, cada vez mais o conhecimento científico passou a ser o insumo mais importante de um número crescente de tecnologias (Sabato, 2011 [1975]) e a importância econômica crescente da ciência e a ampla institucionalização da pesquisa foram responsáveis pelas mudanças técnicas (Mowery; Rosenberg, 2005 [1998]). As inovações técnicas e organizacionais neste período abriram uma trajetória nova para a organização interna das empresas e sua interação com o mercado, alterando a dinâmica de acumulação de capital.

(9) "Until coal provided a cheap and flexible source of energy and until the railroad made possible fast, regular all-weather transportation, the processes of production and distribution continued to be managed in much the same way as they had been for half a millennium" (Chandler Jr., 1999, p. 485). O estabelecimento das redes de transporte e de comunicação foi necessário para o surgimento da produção e distribuição em massa e para a ascensão da 'empresa moderna' (Chandler Jr, 1999). 
Os conhecimentos que no período anterior estavam principalmente corporificados nos trabalhadores (human-embodied technologies), pois eram basicamente conhecimentos tácitos, no Paradigma da Produção em Massa a tecnologia tem um caráter que possibilita a sua codificação. A codificação do conhecimento também já era percebida no período anterior, sobretudo quando as máquinas-ferramenta mecânicas e instrumentos tornaram-se mais complexos e passaram a ter cada vez mais tecnologias incorporadas, no entanto, no Paradigma da Produção em Massa a codificação, com a ajuda da ciência, torna-se 'corriqueira', e passa a corporificar o capital.

Houve esforços intensivos para melhorar a proteção do patrimônio tecnológico e tornaram-se mais claros e robustos os direitos de propriedade intelectual, salvaguardando os novos conhecimentos e tecnologias gerados dentro das empresas (Mowery; Rosenberg, 2005 [1998]). Dessa forma, as tecnologias passaram a ser cedidas por meio de licenciamentos, sendo os contratos utilizados para esses fins um importante meio de transferi-las. A informação e o conhecimento científico e tecnológico passaram a formar uma totalidade complexa e ganharam expressão. Por essa razão, os direitos de propriedade intelectual e as rendas tecnológicas assumem importância neste Paradigma Tecnológico.

Além das Revoluções dos Transportes e das Comunicações (que ocorreram no período anterior), a eletricidade, o motor a combustão e as inovações organizacionais fordistas-tayloristas contribuíram para alterar a estrutura da indústria, dando forte impulso à produção (Fohlen, 1980). Por exemplo, as mudanças organizacionais, com a produção e distribuição em massa, dominaram a economia mundial no quartel que sucede à Segunda Guerra Mundial ${ }^{10}$, influenciando fortemente o comportamento dos consumidores e da própria tecnologia de produção em ramos industriais diversos, sobretudo dos bens duráveis de consumo (Freeman; Soete, 2008 [1974]), os quais passaram a corporificar tecnologia.

O processo de concentração e centralização de capital nos EUA (centro dinâmico do novo paradigma) marcou uma expansão colossal das novas empresas gigantes em território americano e se expandiu, subsequentemente, para além das fronteiras nacionais, sobretudo rumo à Europa. Juntamente com a expansão das empresas em âmbito internacional, houve uma ampliação da TIT. Primeiramente por via de exportações de bens e serviços americanos, passando pelo estabelecimento de organizações de vendas desses bens no exterior (transferindo, portanto, conhecimento organizacional), seguido pela concessão de licenças para o

(10) Certamente o período das guerras mundiais marca um processo de redução de transferência de tecnologia. De acordo com Nelson e Wright (1992), o processo global de difusão e de adaptação de métodos americanos teria certamente continuado (ou por imitação ou por IDE) se não fosse interrompido pela Segunda Guerra Mundial. 
uso de suas patentes, marcas e know-how a empresas estrangeiras (e suas filiais no exterior) que produzem e vendem seus bens. Portanto, diferentemente do período anterior quando a mobilidade de trabalhadores qualificados (e mais tarde máquinas) era o principal canal de TIT, nesse momento, um canal importante é o licenciamento tecnológico, graças à expansão das empresas (americanas, mas não somente elas) para outras regiões. A difusão de tecnologia industrial e das técnicas administrativas norte-americanas (sobretudo para Europa e Japão) ${ }^{11}$ se deu também por meio de políticas estabelecidas pelo governo americano, como o Plano Marshall, que imprimiu grande ênfase na transferência de tecnologia e a Organisation for European Economic Co-operation - OEEC (hoje Organisation for Economic Co-operation and Development - OECD), que incentivou o envio de equipes de pesquisadores para estudar a produtividade dos EUA em empresas norte-americanas nos primeiros anos após a Guerra (Freeman; Soete, 2008 [1974]). Ademais, o sistema militar norte-americano foi um importante canal de transferência de tecnologia ${ }^{12}$ (Westphal; Kim; Dahlman, 1985).

No imediato pós-guerra, durante o período de reconstrução, os métodos americanos - produção contínua, especialização, replanejamento das plantas produtivas, adoção dos princípios e métodos tayloristas - foram amplamente reconhecidos pelas empresas alemãs (Jevons, 1931). A industrialização por cópia foi um fato comum do pós-guerra, o que levou os seguidores à formação de sistemas de inovação voltados à adaptação e ao encurtamento do ciclo do produto (estratégia praticada de forma bem-sucedida pelo Japão, por exemplo) (Medeiros, 2013).

Houve um processo de difusão de inovações organizacionais intensas e as empresas multinacionais americanas foram um importante fator para a transmissão

(11) No pós-guerra, devido a crescente interdependência da economia dos países europeus, a TIT foi ampliada e se deu por meio do comércio de bens de capital, acordos de licenciamento e IDE. Tal interdependência possibilitou a exploração do uso de economias de escala e as altas taxas de investimento nas economias europeias encorajaram uma rápida difusão das 'melhores práticas' americanas (Pavitt, 1985). O emparelhamento das economias europeias no pós-guerra com a economia americana foi possível, dentre outros fatores, porque estes países possuíam um nível relativamente alto de tecnologia endógena acumulada (Pavitt, 1985).

(12) Um exemplo emblemático é o caso da Coreia do Sul que, com a guerra da Coreia, recebeu uma 'contribuição' dos EUA para seu processo de emparelhamento tecnológico. Pode-se dizer que o desenvolvimento econômico da Coreia do Sul, bem como da Alemanha e Japão (logo após a Segunda Guerra), resultaram de 'convite' dos EUA, daí a noção de 'desenvolvimento a convite' (Fiori, 2013). As decisões de desenvolvimento não se dão exclusivamente internamente. As relações entre os grupos econômicos e sociais de cada nação estão vinculados com outras nações, em particular com o Estado hegemônico, por meio de oportunidades econômicas, modelos e ideologias (Medeiros, 2013). De acordo com Medeiros (2013), o contexto da Guerra Fria, por exemplo, influenciou o acesso a divisas e tecnologia e teve apoio ou veto (e até mesmo bloqueio) às estratégias de desenvolvimento dos países que se industrializaram no pós-guerra por parte dos EUA. Por exemplo, no caso sulcoreano houve grande apoio dos EUA na provisão inicial de financiamento externo e de mercado preferencial para suas exportações (Medeiros, 2013). 
da tecnologia americana para potenciais competidores estrangeiros (Mansfield et al., 1982). As empresas americanas (a 'moderna corporação') que estabeleceram filiais no exterior transferiram os princípios de administração e de organização tipicamente americanos (administração científica) (Nelson; Wright, 1992) e tiveram um efeito demonstração não desprezível.

\section{A TIT no paradigma das TICs}

O novo paradigma tecnológico baseia-se em um conjunto de inovações em computação eletrônica, engenharia de software, sistemas de controle, circuitos integrados e telecomunicações, por isso chamado de paradigma das TICs. Os limites técnicos regulatórios e mercadológicos que antes separavam os diferentes segmentos da indústria são, a partir deste paradigma, rompidos pela possibilidade da incorporação de dispositivos eletrônicos em uma gama imensa de produtos e da sua integração ao mundo digital (Tigre; Ripper; Roselino, 2010).

Tais inovações reduziram drasticamente o custo de conservação, processamento, comunicação e disseminação da informação (Perez, 2002) e possibilitaram a fragmentação do processo produtivo (Grossman; Rossi-Hansberg, 2006).

Com o novo paradigma, o cenário econômico passou a mover-se de modo ainda mais dinâmico e o padrão de industrialização, que fora liderado pelos complexos metalmecânico e químico, passou a ser condicionado pelas novas tecnologias (microeletrônica, informática, telecomunicações, automação), pela busca de novos materiais e energias e pela biotecnologia. Embora as TICs marquem um novo paradigma tecnológico, elas não romperam totalmente com o padrão de acumulação anterior baseado na produção em massa fordista, mas ajudaram a rejuvenescer setores maduros como o químico-petroquímico e a própria indústria automobilística (carro-chefe do paradigma anterior) (Cassiolato; Gadelha; Albuquerque; Tigre; Cavalcanti, 2010).

Além disso, verifica-se um processo de reestruturação internacional de diversas indústrias e uma significativa aceleração no ritmo de inovação tecnológica em muitas delas. Há mudanças essenciais em nível da organização industrial, do comportamento e da estrutura da firma e, em consequência, das estratégias corporativas correspondentes (Vera - Vassallo, 1996).

O desabrocho do novo paradigma tecnológico acelerou radicalmente o processo de transformação das formas de organização, concorrência e gestão das empresas transnacionais. A obsolescência do padrão tecnológico implementado pelos países de industrialização tardia foi uma consequência imediata (Mariutti, 2011). 
A emergência de novas tecnologias expandiu a fronteira do conhecimento humano e também proveu meios para aumentar as capacidades comerciais (Simon, 1991), dando o suporte ‘técnico’ para o processo de globalização. Há, certamente, elementos que marcam particularidades da TIT neste novo paradigma.

A TIT ganhou novos contornos. A partir dos anos 1980, devido ao caráter pervasivo das $\mathrm{TICs}^{13}$, a produção foi ganhando sistematicamente característica de redes, em que a grande empresa passa a terceirizar atividades (outsourcing) não consideradas principais e se concentra no core business. Ademais, a grande empresa capitalista passou a adquirir e ampliar vantagens competitivas (ativos) por intermédio de sua rede de filiais e subsidiárias (Gomes, 2003), subcontratando fornecedores atacadistas especializados e altamente capacitados, criando verdadeiros oligopólios mundiais. (Chesnais, 2013) e se estruturando em cadeias globais de valor (Gereffi; Humphrey; Sturgeon, 2005).

No que tange à TIT, o processo de sourcing das grandes corporações transnacionais pode permitir vantagens dinâmicas aos países anfitriões, colocando pressão na indústria doméstica para que se reestruture e se modernize por meio da transferência de tecnologia, portanto, o processo de fragmentação da produção pode fomentar o aprimoramento de aptidões de produção, mas também de aptidões tecnológicas (Radosevic, 1999a). Sob certas condições, as grandes corporações transnacionais e diferentes tipos de fragmentação da produção podem aumentar a aptidão local, assistir à disseminação de novas tecnologias para fornecedores e consumidores, aumentar a qualidade de produto e estimular a competição local (Radosevic, 1999a).

A produção e as trocas internacionais passaram a ser dirigidas de forma integrada e possibilita a valorização dos recursos do capital concentrado, o qual está em condição de operar internacionalmente e de aproveitar as disparidades existentes entre os diferentes espaços que compõem a economia mundial (Furtado, 1999). A escala de produção ${ }^{14}$ é aproveitada neste sentido e também a defasagem entre as amplitudes da ação das transnacionais e das do Estado (cuja ação está inscrita no espaço nacional).

(13) A microeletrônica resolveu alguns desafios impostos pela sociedade industrial: diminuição de tempos mortos, controle e gerenciamento de informações e aumento da variedade de insumos e produtos (Ferraz; Kupfer; Haguenauer, 1996). Devido ao caráter pervasivo das TICs, há desafios e oportunidades não só para o próprio setor, mas também para toda a economia. Ademais, mesmo com avanços contínuos, as TICs não são consideradas tecnologias maduras, podendo evoluir com inovações incrementais bem como com inovações radicais (Cassiolato et al., 2010).

(14) Devido ao seu tamanho, as grandes corporações conseguem usufruir de economias de escala e de escopo. Ademais, de acordo com Penrose (2006) existem outras economias que são somente possíveis se a empresa for grande. São elas: economias de tamanho (economias tecnológicas, economias administrativas, economias na expansão e economias no funcionamento) e economias de crescimento. As economias atribuídas ao tamanho possibilitam vantagens competitivas, permitindo a expansão da grande empresa em determinadas direções, mas não estariam disponíveis se a empresa fosse menor. 
O mercado mundial por um lado potencializa as atividades dos grandes (ganhos em escala de produção e acesso a recursos) e por outro restringe aquelas que não possuem recursos necessários para nele entrar (Furtado, 1999). O processo de globalização notabiliza-se pelo papel protagonista desempenhado pela empresa transnacional como agente de geração de tecnologia, de fluxos comerciais e de investimentos externos diretos (Chesnais, 1996; Machado, 2010). Nota-se, desde então, além da crescente fragmentação da produção stricto sensu, uma crescente globalização da tecnologia embora os investimentos em P\&D estejam entre as despesas industriais mais concentradas do mundo e pode-se afirmar que a $\mathrm{P} \& \mathrm{D}$ nunca foi fragmentada no mesmo grau da produção (Chesnais, 1996). De acordo com Carlsson (2006) não há dúvidas de que as atividades de P\&D empresariais estão cada vez mais internacionalizadas, embora o grau de internacionalização varia entre países e setores

Pode-se entender a globalização da tecnologia como uma reconfiguração das atividades tecnológicas das grandes empresas multinacionais no sentido de ampliar a fragmentação de suas atividades no plano global. No entanto, não há um consenso de que a tecnologia está se tornando global mesmo que as atividades de P\&D estejam cada vez mais internacionalizadas, pois ainda há evidências que comprovam que as atividades tecnológicas estão localizadas no país sede. Há ainda resultados de pesquisas, como demonstra Carlsson (2006), que comprovam que o grande crescimento da internacionalização ocorreu como resultado de fusões e aquisições de empresas em outros países que já possuíam laboratório de P\&D e não como um crescimento orgânico e intencional de criar centros de $\mathrm{P} \& \mathrm{D}$ no exterior. No imediato pós-guerra, as atividades de P\&D foram internacionalizadas apenas até certo limite e a maioria estava voltada em adaptar produtos a mercados específicos. Já na década dos 1990 as firmas começaram a contar com redes internacionais para explorar a competência de centros de $\mathrm{P} \& \mathrm{D}$ de excelência, no entanto, o país sede da empresa ainda é o local mais importante de desenvolvimento tecnológico da empresa e as atividades tecnológicas desenvolvidas no exterior são less science-based e menos dependentes de conhecimentos tácitos que são desenvolvidos em casa (Carlsson, 2006).

A internacionalização da tecnologia pelas multinacionais não se limita a suas atividades de $\mathrm{P} \& \mathrm{D}$, de acompanhamento tecnológico e de centralização e apropriação de conhecimentos. Inclui medidas tomadas pelos grupos para proteger suas tecnologias privadas e impedir que sejam imitadas ou utilizadas sem a concordância dos proprietários, conforme as leis de patentes e instrumentos jurídicos internacionais. 
No pós-1980, o investimento direto externo (IDE ${ }^{15}$ ) torna-se um vetor importante da economia mundial e um relevante canal para TIT. Seu crescimento adquiriu tal magnitude que a importância do investimento na constituição das interdependências entre nações tornou-se perceptível até nas estatísticas e muitos estudos demonstraram que o aumento do IDE estava ligado às estratégias empresariais relacionadas à aquisição e diversificação tecnológica, embora variassem ao longo do tempo (Carlsson, 2006).

\section{A TIT e a superação do atraso}

Existem vários exemplos de Estados Nacionais que, com uma estratégia 'adequada', conseguiram complementar seu processo de desenvolvimento industrial com a importação de tecnologias e conhecimentos, como é o caso do 'Bando dos Quatro'16 (Pack, 2005), no século XX (Kim, 2005, 2005 [1997]; Pack, 2005; Viotti, 2002). E o fizeram como uma imposição de sobrevivência de suas nações, não como uma escolha. O acesso a tecnologias e conhecimentos externos foi fundamental para a construção de habilidades nacionais próprias (Freeman \& Soete, 2008 [1974]; Kim, 2005 [1997]; Rosenberg, 1976; Viotti, 2002).

Há, portanto, evidências concretas que comprovam que nações quando retardatárias cresceram ao explorar efetivamente um conjunto de tecnologias disponíveis pelas nações líderes (Radosevic, 1999a). Explorar efetivamente, neste contexto, significa mais do que simplesmente 'tomar emprestado' ou adquirir soluções prontas, mas um esforço ativo de empresas nacionais retardatárias de dominar vários elementos da tecnologia importada, com apoio do Estado. É inegável que a tecnologia adquirida além do território nacional pode proporcionar um 'insumo' inicial importante para o aprendizado tecnológico da nação importadora, embora não seja por si só um substituto para o desenvolvimento de aptidões locais (Lall, 2005; Nelson; Wright, 1992).

Obter tecnologias e operá-las adequadamente geralmente requer um processo de learning-by-doing, por parte de engenheiros e gerentes para operarem as máquinas importadas, bem como requer investimentos em instalações e demais equipamentos auxiliares. Assim, a TIT, a partir dos exemplos históricos apresentados, envolveu muito mais do que o conhecimento corporificado em algumas pessoas, ou alguns desenhos e modelos. Estes podem fornecer um começo rumo ao emparelhamento tecnológico, mas o comando real da tecnologia

(15) O IDE, sobretudo o tipo greenfield (construção de novos ativos) e na forma de F\&A de ativos públicos e privados (já constituídos domesticamente), é importante canal de TIT, pois as multinacionais transferem tecnologia de diferentes maneiras: "they [the multinational firms] train operatives and managers, communicate information and capabilities to engineers and technicians, help the user of their products to use them more effectively, and help suppliers to upgrade their technology” (Mansfield et al.,1982, p. 17).

(16) O ‘Bando dos Quatro’ é formado por Hong Kong, Coreia do Sul, Cingapura e Taiwan. 
requer uma quantidade considerável de aprendizagem organizacional (tentativa e erro) (Nelson; Wright, 1992), a qual é local e historicamente dependente (pathdependent) (Malerba; Orsenigo, 1993).

Ademais, existem vínculos que não são estabelecidos pelo mercado, mas por outros fatores, como pelo capital social, educação, política e sentimentos nacionais de um povo (Putman, 2005; Silveira, 2001). Existem diferenças marcantes entre nações sobre como o processo de aprendizado ocorre, em termos institucionais e organizacionais, e isto possui implicações não menosprezáveis para a história do desenvolvimento das nações (Bruland, 1998).

A TIT requer um aparato institucional capaz de explorar as oportunidades tecnológicas (potencialidade das inovações e dos aperfeiçoamentos) disponíveis internacionalmente e que as complemente com uma acumulação tecnológica doméstica $^{17}$ (Radosevic, 1999a). O exposto sugere que tanto o processo de TIT quanto o contexto em que ocorrem são relevantes na compreensão de o porquê algumas nações terem feito bom uso das oportunidades externas e o porquê outras não. Ademais, as oportunidades tecnológicas são dinâmicas e ajudam a moldar o sistema econômico; assim, respostas a elas devem acompanhar tal dinâmica.

Ferrer (1976) sugere que não se pode conceber uma TIT efetiva, o fortalecimento da capacidade doméstica de inovar e a adaptação dos conhecimentos importados sem que se incorporem ao sistema produtivo as atividades líderes do crescimento e da mudança técnica. De acordo com Radosevic (1999b), não basta habilidades educacionais em âmbito macro e know-how em âmbito específico das organizações (que são capacidades cumulativas e essenciais para o emparelhamento tecnológico), mas a interação entre esses níveis ${ }^{18}$. Rosenberg (2006 [1982]) complementa afirmando que são necessários altos níveis de habilidades e competências técnicas dos países receptores da tecnologia

(17) Albuquerque (1998) lembra que a introdução de inovações decorre de dois elementos relacionados: oportunidades tecnológicas e condições de apropriação das inovações. Oportunidades tecnológicas podem ser criadas por avanços científicos, por avanços tecnológicos realizados em outras indústrias e por feedbacks com tecnologia (Klevorick, Levin, Nelson, \& Winter, 1995). “A capacitação tecnológica da firma é pressuposto básico para que as oportunidades tecnológicas possam ser aproveitadas ( $\mathrm{P} \& \mathrm{D}$, processo produtivo, capacitação organizacional etc.)" (Albuquerque, 1998, p. 69). De acordo com Dosi (1988), tanto as oportunidades tecnológicas quanto as condições de apropriabilidade são específicas a cada paradigma tecnológico.

(18) "Without the intensive technological effort at the enterprise level a high general level of education is insufficient for technological catching up" (Radosevic, 1999b, p. 436). "The development of indigenous technological capability is dependent upon the following: the length of experience with industrial activity; the capability of the economy to assimilate technology (which is function partly of the availability of skilled work force and partly of experience itself); the organizational and managerial capabilities of the firms concerned; the existence of a capital-goods sector (which depends largely on the size of the economy and the sort of industrialization strategy pursued); and the technological policy followed by the government" (Lall, 1980, p. 42). 
transferida, o que significa dizer que a TIT bem-sucedida exige investimentos substanciais no aprendizado (absorção ${ }^{19}$ ) e na adaptação locais (Amsden, 2009).

A nosso ver, não existe exemplo na historiografia que demonstre que somente a TIT seja suficiente para superar o atraso relativo (e não é, em absoluto, a tese aqui proposta). A Prússia (parte do que hoje corresponde ao território alemão) contou pesadamente com a TIT (importação de máquinas-ferramenta mecânicas, espionagem etc. $)^{20}$, porém havia desenvolvido, ainda no século XVI, um sistema de escolas técnicas e havia cultivado a pesquisa em ciências naturais em universidades, o que auxiliou sua independência científica (Borchardt, 1987), mesmo quando a ciência ainda estava desvinculada da tecnologia. Sua base industrial consolidou-se apoiada em inovações tecnológicas intimamente ligadas ao seu modelo educacional: a educação elementar era compulsória e as escolas tinham alto nível, demonstrando que os prussianos desenvolveram suas instituições educacionais previamente, como preparação para a industrialização, com investimentos pesados em capital social (Braga, 1999).

Outro exemplo histórico importante é encontrado no caso escandinavo (Suécia, Dinamarca e Noruega), cujo processo de desenvolvimento esteve sempre ligado a um elevado nível de importação de tecnologia e seu processo de emparelhamento teve como um dos fatores primordiais a preocupação com a formação elementar formal (especialmente formação em engenharia) de jovens (Bruland, 1998).

Um caso notável é o finlandês. A Finlândia, no século XIX, com uma população relativamente pequena, isolada do restante da Europa e com características climáticas ${ }^{21}$ que limitavam a agricultura, importou (sobretudo da Alemanha e Inglaterra) bens de consumo e bens de capital, nos quais a tecnologia

(19) De acordo com Soete (1985, p. 415): “The country's absorptive capacity, i.e., the extent to which it can rapidly and efficiently introduce into its economic structure foreign technology, will also be crucial". E continua (p. 416): "the actual success of such a strategy [adopt imported technology] is obviously subject to many conditions some of which - for example managerial, educational and training levels, risk readiness, skill requirements both to operate and maintain the imported technology, capacity to assess its value and profitability to adopt".

(20) "Many German merchants and officials visited Britain towards the end of the eighteenth and in the nineteenth centuries to study the innovation and to transmit to Germany their newly acquired knowledge (...). Until after the middle of the nineteenth century the imitation of foreign models remained of major importance. Not merely machinery but 'social inventions' were copied, i.e. new commercial institutions, mercantile techniques, maxims of economics policy and administrative postures.(...) British capital goods were especially important in the establishment of German industry. The first German railways from 1835 on, for instance, were largely equipped with British engineers, wagons and rails" (Borchardt, 1987, p. 82-83).

(21) "The climate set strict limits for agriculture in nineteenth-century Finland. Because the mean annual temperature was low $(+4.6 o \mathrm{C}$ in Helsinki and $+2.00 \mathrm{C}$ in central Finland) and summers were short, only few grains and other plants could be cultivated. For instance, wheat could be grown only in the southern provinces. Only one crop was harvested annually as snow covered the ground from 3 to 7 months a year (...). (...) Ice closed Finnish sea ports for at least 3 months a year" (Myllyntaus, 1990, p. 628-629). 
da época estava corporificada. As referidas dificuldades serviram como estímulo ao seu processo endógeno de industrialização por substituição de importações entre 1830 e 1890. Ademais, o Estado finlandês concentrou esforços para o desenvolvimento do sistema de transportes, investiu na modernização da educação primária, técnica e superior, além de ter promovido missões de estudo no exterior como forma de adquirir conhecimento e tecnologia (Myllyntaus, 1990).

Igualmente, o Japão representa um caso admirável ${ }^{22}$ : para diminuir o atraso relativo, no final do século XIX, o governo nipônico patrocinou a ida de japoneses para a Europa e EUA, tanto para ratificar diversos tratados antigos firmados, como para assimilar a cultura ocidental; além disso, contratou diversos especialistas estrangeiros como conselheiros (os especialistas alemães ocupavamse em organizar novas universidades e escolas de medicina e até mesmo auxiliaram na redação de uma constituição; os conselheiros norte-americanos contribuíram com a criação de centros agrícolas e com um serviço nacional de correios; os britânicos dedicaram-se ao desenvolvimento de ferrovias, telégrafo e de obras públicas e o exército contava com instrutores militares franceses; os italianos foram requeridos para revelarem os segredos da arte ocidental) (Hall, 1984).

A modernização japonesa apoiou-se em uma forte imitação da cultura ocidental: a civilização ocidental era útil devido à sua técnica, mas os japoneses estavam convencidos de que seus valores espirituais e éticos eram superiores aos dos ocidentais e os preservaram, conservando seu sentimento de identidade cultural frente à influência estrangeira (Hall, 1984). O governo logo identificou a

(22) O Japão constitui um caso excepcional de desempenho econômico acelerado (em termos reais cresceu a uma taxa de $9,5 \%$ a.a. por duas décadas) no pós-guerra graças a uma mudança em sua estrutura produtiva, ou seja, alterando a pauta e a composição do produto, gerando novas relações inter e intraindustrias. Segundo Torres (1983), o principal fator de explicação do dinamismo da economia japonesa encontra-se no acirramento e na mudança das condições de concorrência entre os grandes grupos nacionais (as empresas passaram por transformação, organizando-se em keiretsu). O planejamento público (por meio do Ministério da Indústria e de Comércio Exterior - MITI) e as características dinamizadoras dos setores que foram implantados ou modernizados seguindo suas diretrizes também podem ser encarados como fatores de explicação desse processo de crescimento acelerado. Ademais, a importação de tecnologia estrangeira, juntamente com políticas de fomento à P\&D foram estimuladas (Bell; Cassiolato, 1993). O padrão de industrialização do Japão contou com um protecionismo que possibilitava um processo de aprendizado liderado por grupos nacionais vinculados com o Estado nipônico, articulados em torno dos complexos químicos e metalmecânico com vistas a conquistas futuras do mercado internacional (Fajnzylber, 1983). As políticas japonesas foram projetadas de modo a criar uma relação de complementaridade entre a importação de tecnologias e habilidades estrangeiras e o learn-by-doing local. Os termos de transferência tecnológica foram controlados, de modo a permitir que os engenheiros locais aprendessem com ela (engenharia reversa foi uma prática comum). O controle direto por parte das empresas estrangeiras foi fortemente desencorajado (Cooper, 1972). De acordo com Mazzucato (2013), o crescimento acelerado japonês é explicado a partir dos fluxos de conhecimento por meio de uma estrutura econômica mais horizontal articulando MITI, academia e P\&D privado. Finalmente, um fator importante abrange a capacidade histórica dos japoneses de assimilar culturas alheias, seu esforço nacional contínuo de emparelhar com o ocidente desde meados do século XIX e a breve autarquia tecnológica durante a Segunda Guerra Mundial (Ozawa, 1985). 
relevância de um aprimoramento tanto de capacidades de gestão quanto de capacidades técnicas, assim como de habilidades de trabalho (Gold, 1991).

No imediato pós-guerra, o governo japonês teve papel importante na determinação de quais tecnologias deveriam ser importadas e quais empresas e setores deveriam aplicá-las; além disso, investiu recursos maciços em P\&D (Mansfield et al., 1982). Ademais, as políticas públicas japonesas tiveram importante papel na criação de condições que aumentassem as pressões competitivas sobre as empresas nipônicas de maneira a estimular, ao invés de conter, o investimento em capacitação tecnológica (ampliando as aptidões tecnológicas) para complementar a aquisição de tecnologia estrangeira (Bell; Cassiolato, 1993). O Estado japonês seguia um projeto de longo prazo que implicava reservar o mercado interno para a expansão e aprendizagem de uma indústria que buscava alcançar um nível de excelência que a permitiria penetrar e consolidar posições nos mercados internacionais (Fajnzylber, 1983).

Pode-se verificar que o processo de desenvolvimento industrial japonês foi caracterizado pela sequência histórica: compras de tecnologias, adaptação, modificação e melhora, inovação secundária e difusão de tecnologias, o que permitiu que o país entrasse em certos setores com inovações originais (Carrere, 2011 [1975]).

Outros exemplos mais contemporâneos podem ser citados para ilustrar a importância de investimentos públicos na produção do conhecimento, como o caso dos países do leste asiático - a Coreia do Sul é o exemplo emblemático ${ }^{23}$ (Kim,

(23) A Coreia do Sul deu grande importância à expansão da educação com apoio norte-americano (Westphal et al., 1985). Durante os anos 1970, o governo sul coreano passou a dar prioridade ao desenvolvimento tecnológico e as atividades de exportação tornaram-se parte integral do esforço do governo em promover a aquisição de capacidades tecnológicas. Foram tomadas medidas que fomentassem a educação e o treinamento de pessoal qualificado em vários setores e foi criada uma infraestrutura de institutos de C\&T com o intuito de servir à industria, além da criação do Ministério da C\&T e o Instituto Coreano de C\&T (Westphal et al., 1985). A Coreia do Sul foi bem-sucedida na sua transição para um 'Sistema Nacional de Aprendizado Ativo': o país fez esforços extraordinários para erradicar o analfabetismo, ampliar a rede de ensino básico e médio e melhorar o ensino superior. O país foi capaz de desenvolver rapidamente e de forma eficaz uma força de trabalho bem educada e treinada (Viotti, 2002). Ademais, a Coreia contou pesadamente com a TIT para se emparelhar e o principal canal utilizado foi a importação de bens de capital, enquanto que o IDE teve papel minoritário (Pack, 2005; Viotti, 2002). De acordo com Viotti (2002), a importação de bens de capital desempenhou papel relevante no processo coreano de mudança técnica sugerindo que a aquisição de inovações geradas em países industriais avançados (incorporadas em novas safras de bens de capital importados) contribuiu de forma decisiva para manter a Coreia em um ritmo dinâmico de absorção de tecnologia. Igualmente ao modelo de desenvolvimento japonês, o coreano não se apoiou na presença das multinacionais, havendo uma política explícita de promoção da independência em relação a elas (Kim, 2005 [1997]). Outro canal utilizado pela Coreia do Sul foi à importação de produtos tecnológicos de nações relativamente mais avançadas como os EUA e Japão (Viotti, 2002). Ao lado das importações de bens de capital e de produtos tecnológicos, o governo coreano empreendeu políticas ativas de comércio e industriais, as quais foram responsáveis por estimular o dinamismo tecnológico das empresas industriais (Viotti, 2002). De acordo com Viotti (2002), as políticas públicas coreanas possibilitaram a superação dos limites impostos por um 'aprendizado passivo'. Portanto, o Estado sul-coreano assumiu papel ativo na 
1999, 2005 [1997]). Em suma, as instituições educacionais (com a formação de aptidões e esforço para absorver o conhecimento do exterior) desempenharam relevante papel para que os países conseguissem, juntamente com a TIT, realizar o emparelhamento (Mazzoleni; Nelson, 2006).

Destaca-se, portanto, que todos os países que hoje estão na fronteira tecnológica e são conhecidos pelo seu estoque de conhecimento iniciaram o processo de emparelhamento por meio de cópia, imitação e importação de tecnologia, à exceção da Grã-Bretanha. Tal constatação havia sido feita por Albuquerque (1998) e aqui foi corroborada pelos fatos históricos apresentados. De acordo com o autor, a imitação e a cópia representam momentos necessários para o alcance da fronteira tecnológica, conforme tem sido sustentado nesta tese.

Entretanto, não apenas a TIT, mas outros fatores são relevantes para o entendimento de porque algumas nações conseguirem emparelhar e outras não. A TIT foi importante; a aptidão tecnológica e um ambiente propício ao aprendizado o foram também. Tudo com forte apoio dos Estados-Nação. Inclusive, políticas de privatização do conhecimento foram desestimuladas, pois havia entendimento que a propriedade intelectual (patente, sobretudo) era um obstáculo e era prejudicial à prosperidade nacional. Holanda e Suíça (mas não apenas elas) não possuíam um sistema de patentes, o que deu às pequenas empresas nascentes, proteção e maiores chances de sobreviver. Desse modo, sem ter que pagar royalties, tanto à Holanda quanto a Suíça puderam produzir mercadorias de qualidade similar às estrangeiras, com menores custos. De 1850 a 1907, a Suíça não possuía lei de patentes, enquanto que a Holanda restabeleceu sua legislação patentária apenas em 1912 e até esse período seguia imitando, copiando e modificando invenções alheias (Sell, 2004).

implementação da estratégia coreana de industrialização (Kim, 2005; Laplane \& Ferreira, 2013). O fomento aos chaebols (versão coreana dos zaibatsu japoneses) impulsionou a locomotiva industrial: os chaebols desempenharam papel expressivo na aceleração do aprendizado tecnológico do setor industrial ao financiar a TIT tirando proveito de sua capacidade de obter conhecimentos explícitos e implícitos de alto nível da comunidade internacional (Kim, 2005). De acordo com Kim (2005), apesar da concentração de poder econômico, os chaebols promoveram o fortalecimento das aptidões tecnológicas locais e a liderança da globalização dos empreendimentos sul-coreanos, já que possuíam os necessários recursos organizacionais, técnicos e financeiros. Kim (2005) ressalva que à medida que a Coreia vai se aproximando da fronteira tecnológica, outros desafios se fazem presentes, como a crescente dificuldade da aquisição de tecnologias necessárias dos fornecedores estrangeiros. Quando as tecnologias eram relativamente mais simples e vinculadas a um padrão tecnológico do tipo do Paradigma Fordista e as patentes já tinham expirado, as empresas sul-coreanas com capacidade suficiente realizavam a engenharia reversa dos produtos estrangeiros, produzindo cópias baratas. Quando as tecnologias passaram a ser mais complexas, o licenciamento foi o principal canal de TIT utilizado, permitindo que as empresas sul-coreanas adquirissem conhecimento tácito - via treinamentos e supervisões - e conhecimento explícitos - por meio de planos técnicos, especificações de produtos e manuais de produção (Kim, 2005). Quando as patentes ainda estavam em vigor, com a ajuda dos institutos públicos de $\mathrm{P} \& \mathrm{D}$, algumas empresas sul-coreanas puderam desenvolver aptidões para descobrir segredos tecnológicos. No caso de tecnologias emergentes, as empresas estrangeiras protegiam e relutavam ainda mais em transferir tecnologia às empresas sul-coreanas (Kim, 2005). Nas palavras de Chang (2004), as nações relativamente mais avançadas 'chutam a escada'. 
Os EUA, por exemplo, concediam diretos às patentes somente aos cidadãos americanos; inovações estrangeiras não tinham seu direito patentário reservado. Isso permitiu que invenções estrangeiras pudessem ser introduzidas nos EUA, sem que houvesse qualquer pagamento pelo direito de monopólio do inventor. Os EUA, portanto, tiveram acesso a tecnologias de outras nações a um custo relativo menor do que as demais (Sell, 2004).

A TIT é de fato válida quando transforma a estrutura produtiva interna e depende também do nível de tecnologia incorporada ao estoque de capital da nação importadora. Em outras palavras, a TIT pode criar tensões e provocar modificações estruturais positivas no processo produtivo, mas não necessariamente as garante.

Portanto, o ritmo de desenvolvimento econômico de uma nação se encontra indissociavelmente ligado ao ritmo de suas atividades inovativas autóctones e ao fluxo de tecnologia e conhecimento que a mesma recebe do exterior (Bell; Cassiolato, 1993; Biato; Guimarães; Figueiredo, 1973; Dosi; Freeman; Fabiani, 1994; Freeman, 1987; Freeman; Soete, 2008 [1974]; Fu; Pietrobelli; Soete, 2011; Hasenclever; Cassiolato, 1998; James, 1988; Katz, 1976; Pack, 2005; Radosevic, 1999a; Santos, 2014; Viotti, 2002).

\section{Comentários finais}

A TIT foi fundamental para o desenvolvimento das nações desde o surgimento do capitalismo, com a Revolução Industrial Originária e mudanças significativas de canais foram evidenciadas em diferentes paradigmas tecnológicos. A TIT teve incidência sobre o processo de desenvolvimento industrial e sobre o desenvolvimento da capacidade nacional de produção de tecnologias.

Os três períodos esquematicamente identificados estão diretamente ligados às características tecnológicas. Quando a tecnologia estava enraizada nos trabalhadores e com a sofisticação das máquinas-ferramenta mecânicas, a tecnologia passou a estar nelas corporificadas, por isso eram transferidos tanto os trabalhadores quanto as máquinas para que a tecnologia (indiretamente) fosse transferida. À medida que a tecnologia passou a ser relativamente mais complexa e mais produtiva e cada vez mais dependente de novos conhecimentos científicos, a transferência tecnológica e de conhecimento passou a ser possível mediante a meios codificados (licenciamentos pelo uso da propriedade intelectual, for exemplo). Finalmente, com a tecnologia se tornando cada vez mais sistêmica, possibilitando a fragmentação da produção em cadeias globais de valor, foi possível a transferência de normas e métodos de produção, por meio de IDE. O Quadro 1 a seguir resume essas informações. 
Os principais canais de transferência internacional de tecnologia em diferentes paradigmas...

Os canais apresentados foram os principais encontrados em cada paradigma tecnológico estudado, no entanto, não se está dizendo que somente eles foram utilizados, pois a TIT, além de depender da evolução da própria tecnologia e do paradigma tecnológico em questão, também depende do 'grau' de desenvolvimento do país importador e das relações entre diferentes atores em âmbito internacional (isto é, da inserção em plano global de cada Estado Nação e da atuação das grandes corporações). Por isso, há exemplos históricos que mostram que vários canais foram usados simultânea e complementarmente.

Quadro 1

Quadro resumo dos paradigmas tecnológicos e seus principais canais da TIT.

\begin{tabular}{|c|c|c|c|}
\hline $\begin{array}{l}\text { Paradigmas } \\
\text { Tecnológicos }\end{array}$ & $\begin{array}{c}\text { Revoluções Tecnológicas à } \\
\text { La Perez (2002) }\end{array}$ & Período & Principais Canais da TIT \\
\hline $\begin{array}{l}\text { Revolução } \\
\text { Industrial } \\
\text { (Primeira } \\
\text { Revolução } \\
\text { Industrial) }\end{array}$ & Revolução Industrial & $\begin{array}{c}\text { Século } \\
\text { XVIII a } \\
\text { meados do } \\
\text { século XIX }\end{array}$ & $\begin{array}{l}\text { Mobilidade de trabalhadores, } \\
\text { treinamento, espionagem, } \\
\text { contrabando e a importação legal } \\
\text { de ferramentas e máquinas. }\end{array}$ \\
\hline $\begin{array}{l}\text { Paradigma da } \\
\text { Produção em } \\
\text { Massa (Segunda } \\
\text { Revolução } \\
\text { Industrial) }\end{array}$ & $\begin{array}{c}\text { Era do Vapor e das } \\
\text { Ferrovias; Era do Aço, } \\
\text { Eletricidade e Engenharia } \\
\text { Pesada; Era do Petróleo, } \\
\text { Automóveis e Produção em } \\
\text { Massa. }\end{array}$ & $\begin{array}{l}\text { Meados do } \\
\text { século XIX } \\
\text { a meados } \\
\text { do século } \\
\text { XX }\end{array}$ & $\begin{array}{l}\text { Anterior + Exportação de bens e } \\
\text { serviços, estabelecimento de } \\
\text { organizações de vendas desses bens } \\
\text { no exterior (transferindo } \\
\text { conhecimento organizacional), } \\
\text { concessão de licenças para o uso de } \\
\text { suas patentes, marcas e know-how a } \\
\text { empresas estrangeiras (e suas filiais } \\
\text { no exterior). }\end{array}$ \\
\hline $\begin{array}{l}\text { Paradigma das } \\
\text { TICs (Terceira } \\
\text { Revolução } \\
\text { Industrial) } \\
\end{array}$ & $\begin{array}{c}\text { Era da Informação e das } \\
\text { Telecomunicações }\end{array}$ & $\begin{array}{c}\text { Meados do } \\
\text { século XX } \\
\text { em diante }\end{array}$ & $\begin{array}{l}\text { Anterior + Transferência de normas } \\
\text { e métodos de produção, por meio } \\
\text { de IDE e por meio da participação } \\
\text { em cadeias globais de valor. }\end{array}$ \\
\hline
\end{tabular}

Fonte: Elaboração própria.

A proposição de que a importação de novos capitais possa corporificar conhecimento de fronteira e permitir o emparelhamento pode propiciar o avanço industrial, mas não a superação do atraso. A TIT per se não é tão importante, mas sim a efetividade com a qual a 'nova' tecnologia é integrada ao processo produtivo de uma empresa específica, a qual pode adaptá-la. É o processo de aprendizado envolvido e gerado nesse processo que pode fornecer novos produtos e processos e garantir a permanência de empresas e nações em mercados com competição altamente acirrada.

A TIT, portanto, proporciona a modernização tecnológica do país importador, ampliando a capacidade de produção, sem, no entanto, garantir a 
ampliação da aptidão tecnológica doméstica e do rompimento do subdesenvolvimento. A aquisição de tecnologia e conhecimentos pode eventualmente ser eficiente no curto prazo, porém não é a melhor opção de longo prazo já que o desenvolvimento não deriva da mera importação de tecnologias, mas da capacidade doméstica de se estabelecerem sistemas tecnológicos interrelacionados em evolução, capazes de gerar sinergias para processos de desenvolvimento sustentado (Freeman; Soete, 2005). É exatamente esta interconexão entre os sistemas tecnológicos que possibilitam a difusão de conhecimentos, aptidões e experiências, fundamental para o processo de desenvolvimento tecnológico.

\section{Referências bibliográficas}

ALBUQUERQUE, Eduardo Motta. Patentes segundo a abordagem neoschumpeteriana: uma discussão introdutória. Revista de Economia Política, São Paulo, v. 18, n. 4, p. 65-83, 1998.

AMSDEN, Alice H. A ascensão do 'resto': os desafios ao ocidente de economias com industrialização tardia. São Paulo: Editora Unesp, 2009.

ANDREAS, Peter. Smuggler nation: how illicit trade made America. Oxford: Oxford University Press, 2013.

ARTHUR, W. B. The nature of technology. What it is and how it evolves. New York: Free Press, 2011.

BELL, Martin; CASSIOLATO, José Eduardo. The access of developing countires to new technologies: the need for new approaches to management and policy for technology imports in Brazilian industry. Estudo da Competitividade Brasileira. Campinas, SP, 1993.

BIATO, Francisco Almeida; GUIMARÃES, Eduardo Augusto A.; FIGUEIREDO, Maria Helena Poppe de. A transferência de tecnologia no Brasil. Brasília: Ipea/Iplan, 1973.

BORCHARDT, K. The industrial revolution in Germany, 1700-1914. In: CIPOLLA, C. M. (Ed.). The Fontana economic history of Europe: the sixteenth and seventeenth centuries. Barcelona: Editora Arial, 1987. v. 4.

BRAGA, José Carlos de Souza. Alemanha: império, barbárie e capitalismo avançado. In: FIORI, J. L. (Ed.). Estados e moedas no desenvolvimento das nações. Petrópolis: Vozes, 1999.

BRULAND, K. Skills, learning and the international diffusion of technology: a perspective on Scandinavian Industrialisation. In: BERG, M.; BRULAND, K. 
(Eds.), Technological revolutions in Europe: historical perspectives. Cheltenham: Edward Elgar, 1998. p. 161-185.

CARLSSON, Bo. Internationalization of innovation systems: A survey of the literature. Research Policy, v. 35, p. 56-67, 2006.

CARRERE, Maximo Halty. (1975). Producción, transferencia y adaptación de tecnología industrial. In: SABATO, J. A. (Ed.), El pensamiento latinoamericano en la problemática ciencia-tecnología desarrollo-dependencia. Buenos Aires: Ediciones Biblioteca Nacional. 2011. p. 347-380.

CASSIOLATO, José Eduardo, GADELHA, GRABOIS Carlos Augusto, ALBUQUERQUE, Eduardo Motta; TIGRE, Paulo Bastos; CAVALCANTI, Paulo Fernando Moura Bezerra. Introdução. In: CASSIOLATO, J. E. (Ed.). Perspectivas do investimento na economia do conhecimento. Rio de Janeiro: Synergia, 2010. p. 1-6.

CHANDLER JR, A. D. The visible hand: the managerial revolution in American business. Cambridge: Harvard University Press, 1999.

CHANG, Ha-Joon. Maus samaritanos: o mito do livre-comércio e a história secreta do capitalismo. Rio de Janeiro: Elsevier, 2009.

CHESNAIS, François. A mundialização do capital. São Paulo: Editora Xamã. 1996.

CHESNAIS, François. Present international patterns of foreign direct investment: underlying causes and some policy implications for Brazil. Revista de Economia Contemporânea, v. 17, n. 3, p. 376-422, 2013.

COOPER, Charles. Science, technology and production in the underdeveloped countries: an introduction. The Journal of Development Studies, v. 9, n. 1, p. 1-18, 1972.

CRAFTS, Nicholas. Forging ahead and falling behind: the rise and relative decline of the first industrial nation. The Journal of Economic Perspectives, v. 12, n. 2, p. 193-210, 1998.

DOSI, Giovanni. Institutions and markets in a dynamic world. The Manchester School, v. LVI, n. 2, p. 119-146, 1988.

DOSI, Giovanni, FREEMAN, Chris; FABIANI, Silvia. The process of economic development: introducing some stylized facts and theories on technologies, firms and institutions. Industrial and Corporate Change, v. 3, n. 1, p. 1-45, 1994.

FAJNZYLBER, Fernando. La industrialización trunca de América Latina. Ciudad de Mexico: Editorial Nueva Imagen, 1983. 
FERRAZ, João Carlos; KUPFER, David; HAGUENAUER, Lia. Made in Brazil. Rio de Janeiro: Campus, 1996.

FERRER, Aldo. La dependencia científica y tecnológica en el contexto internacional y sus implicaciones para la transferencia de tecnología. Desarrollo Económico, v. 15, n. 60, p. 565-580, 1976.

FIORI, José Luís. Poder, geopolítica e desenvolvimento. Carta Capital, São Paulo, 2013.

FOHLEN, Claude. América anglo-saxônica de 1815 à atualidade. São Paulo: Editora Pioneira. 1980.

FREEMAN, Chris. El reto de la innovación: la experiencia de Japón. Caracas, Venezuela: Editorial Galac, 1987.

FREEMAN, Chris; SOETE, Luc. (1974). A economia da inovação industrial. Campinas, SP: Editora da Unicamp, 2008.

FU, Xiaolan; PIETROBELLI, Carlo; SOETE, Luc. The role of foreign technology and indigenous innovation in the emerging economies: technological change and catching-up. World Development, v. 39, n. 7, p. 1204-1212, 2011.

FURTADO, João. Mundialização, reestruturação e competitividade: a emergência de um novo regime econômico e as barreiras às economia periféricas. Novos Estudos Cebrap, São Paulo, v. 53, p. 97-118, 1999.

GEREFFI, Gary; HUMPHREY, John; STURGEON, Timothy. The governance of global value chains. Review of International Political Economy, p. 78-104, 2005.

GOLD, Bela. Improving the pattern of technology transfer and trade between the United States and Japan. In: AGMON, T.; GLINOW, M. A. V. (Ed.). Technology transfer in international business. New York: Oxford University Press, 1991. p. 240-252.

GOMES, Rogério. A internacionalização das atividades tecnológicas pelas empresas transnacionais. Elementos de organização industrial da economia da inovação. Tese (Doutorado)-Universidade Estadual de Campinas (Unicamp), Campinas, SP, 2003.

GROSSMAN, Gene M.; ROSSI-HANSBERG, Esteban. The rise of offshoring: it's not wine for cloth anymore. Paper presented at the Economic Policy Symposium on The New Economic Geography: Effects and Policy Implications, Jackson Hole, Wyoming, 2006.

HALL, John Whitney. El imperio japonés. Madrid: Siglo Veintiuno de España, 1984. 
HARRIS, John R. Movements of technology between Britain and Europe in the Eighteenth Century. In: JEREMY, D. J. (Ed.), International technology transfer. Aldershot (UK): Edward Elgar, 1991. p. 9-30.

HARRIS, John R. Industrial espionage and technology transfer: Britain and France in the Eighteenth Century. Aldershot: Ashgate Publishing Company, 1998.

HASENCLEVER, Lia; CASSIOLATO, José Eduardo. Capacidad tecnológica empresarial brasileña y transferencia de tecnología. Revista de Economía y Empresas, v. 34, n. XII, p. 15-31, 1998.

HOBSBAWN, Erick. Da revolução industrial inglesa ao imperialismo. Rio de Janeiro: Forense, 1978.

JAMES, Dilmus D. The impact of technology imports on indigenous technological capacity: the case study of Mexico. Working Paper, n. 184. Gevene, Switzerland: World Employment Programme Research at International Organization (ILO), 1988.

JEREMY, David J. Damming the flood: british government efforts to check the outflow of technicians and machinery, 1780-1843. Business History Review, v. 51, n. 01, p. 1-34, 1977.

JEREMY, David J. Transatlantic industrial revolution: the diffusion of textile technologies between Britain and America, 1790-1830s. Oxford: Basil Blackwell, 1981.

JEVONS, H. Stanley. The second industrial revolution. The Economic Journal, v. 41, n. 161, p. 1-18, 1931.

KATZ, Jorge. Importación de tecnología, aprendizaje e industrialización dependiente. Ciudad de Mexico: Fondo de Cultura Económica, 1976.

KIM, Linsu. Building technological capability for industrialization: analytical frameworks and Korea's experience. Industrial and Corporate Change, v. 8, n. 1, p. 111-136, 1999.

KIM, Linsu. O sistema nacional de inovação sul-coreano em transição. In: KIM, L.; NELSON, R. R. (Ed.). Technologia, aprendizado e inovação. As experiências das economias de industrialização recente. Campinas, SP: Editora da Unicamp, 2005. p. 449-483.

KIM, Linsu. (1997). Da imitação à inovação: a dinâmica do aprendizado tecnológico da Coreia. Campinas (SP): Editora Unicamp, 2005.

KLEVORICK, Alvin K.; LEVIN, Richard C.; NELSON, Richard R.; WINTER, Sidney G. On the sources and significance of interindustry differences in technological opportunities. Research Policy, v. 24, n. 2, p. 185-205, 1995. 
LALL, Sanjaya. Developing countries as exporters of industrial technology. Research Policy, v. 9, p. 24-52, 1980.

LALL, Sanjaya. A mudança tecnológica e a industrialização nas economias de industrialização recente da Ásia: conquista e desafios. In: KIM, L.; NELSON, R. (Eds.). Tecnologia, aprendizado e inovação: as experiências das economias de industrialização recente. Campinas, SP: Editora Unicamp, 2005. p. 25-99.

LANDES, David S. Prometeu desacorrentado: transformações tecnológicas e desenvolvimento industrial na Europa Ocidental, de 1750 até os dias de hoje. Rio de Janeiro: Campus, 2005.

LAPLANE, Mariano; FERREIRA, Adriana Nunes. Padrões de crescimento, investimento e processos inovadores: o caso da Coreia do Sul. In: BIELSCHOWSKY, R. (Ed.). Padrões de desenvolvimento econômico (19502008): América Latina, Ásia e Rússia. Brasília: Centro de Gestão e Estudos Estratégicos (CGEE), 2013. v. 2, p. 491-556.

MACHADO, João Bosco M. Integração produtiva: referencial analítico, experiência europeia e lições para o Mercosul. In: ALVAREZ, R.; BAUMANN, R.; WOHLERS, M. (Ed.). Integração produtiva: caminhos para o Mercosul. Brasília: ABDI, 2010. p. 116-155. (Série Cadernos da Indústria ABDI, v. XVI).

MALERBA, Franco; ORSENIGO, Luigi. Technological regimes and firm Behavior. Industrial and Corporate Change, v. 2, n. 1, p. 45-71, 1993.

MANSFIELD, Edwin; ROMEO, Anthony; SCHWARTZ, Mark; TEECE, David; WAGNER, Samuel; BRACH, Peter. Technology transfer, productivity and economic policy. New York: W. W. Norton \& Company, 1982.

MARIUTTI, Eduardo Barros. Crise econômica e rivalidade política: características gerais da ordem internacional contemporânea. In: CARNEIRO, R. MATIJASCIC, M. (Ed.). Desafios para o desenvolvimento brasileiro. Brasília: Instituto de Pesquisa Econômica Aplicada (Ipea), 2011. p. 25-40.

MARX, Karl. (1890). O capital: crítica da economia política. Livro 1: O processo de produção do capital. 10. ed. São Paulo: Difel, 1985. v. 1.

MAZZOLENI, Roberto; NELSON, Richard R. The roles of research at universities and public labs in economic catch-up. Laboratory of Economics and Management Sant'Anna School of Advanced Studies, 2006. (Working Paper, 2006/01).

MAZZUCATO, Mariana. The entrepreneurial state: debunking public vs. private sector myths. New York: Anthem Press, 2013.

MEDEIROS, Carlos Aguiar. Estratégias nacionais de desenvolvimento. In: BIELSCHOWSKY, R. (Ed.). Padrões de desenvolvimento econômico (1950- 
2008): América Latina, Ásia e Rússia. Brasília: Centro de Gestão e Estudos Estratégicos (CGEE), 2013. p. 79-112.

MOWERY, David C.; ROSENBERG, Nathan. (1998). Trajetórias da inovação: a mudança tecnológica nos Estados Unidos da América no século XX. Campinas (SP): Editora Unicamp, 2005.

MYLLYNTAUS, Timo. The finnish model of technology transfer. Economic Development and Cultural Change, v. 38, n. 3, p. 645-643, 1990.

NELSON, Richard R.; WRIGHT, Gavin. The rise and fall of American technological leadership: the postwar era in historical perspective. Journal of Economic Literature, v. 30, n. 4, p. 1931-1964, 1992.

OZAWA, Terutomo. Macroeconomic factors affecting Japan's technology inflows and outflows: the postwar experience. In: ROSENBER, N.; FRISCHTAK, C. (Ed.). International technology transfer: concepts, measures and comparisons. New York: Praeger Publisher, 1985. p. 222-254.

PACK, Howard. A pesquisa e o desenvolvimento no processo de desenvolvimento industrial. In: KIM, L.; NELSON, R. R. (Ed.). Technologia, aprendizado e inovação. As experiências das economias de industrialização recente. Campinas (SP): Editora da Unicamp, 2005. p. 101-134.

PAVITT, Keith. Technology transfer among the industrially advanced countries: an overview. In: ROSENBERG, N.; FRISCHTAK, C. (Eds.). International technology transfer: concepts, measures and comparisons. New York: Praeger Publisher, 1985. p. 03-23.

PENROSE, Edith. A teoria do crescimento da firma. Campinas, SP: Editora Unicamp, 2006.

PEREZ, Carlota. Technological revolutions and financial capital: the dynamics of bubbles and golden ages. Cheltenham: Edward Elgar Publishing, 2002.

PEREZ, Carlota. The double bubble at the turn of the century: technological roots and structural implications. Cambridge Journal of Economics, v. 33, p. 779-805, 2009.

PEREZ, Carlota; SOETE, Luc. Catching up in technology: entry barriers and windows of opportunity. In: DOSI, G.; FREEMAN, C.; NELSON, R.; SILVERBERG, G.; SOETE, L. (Ed.). Technical change and economic theory. London: Francis Pinter. 1988. p. 458-479.

PUTMAN, Robert D. Comunidade e democracia: a experiência da Itália moderna. Rio de Janeiro: Editora FGV, 2005. 
RADOSEVIC, Slavo. International technology transfer and catch-up in economic development. Cheltenham (UK): Edward Elgar, 1999a.

RADOSEVIC, Slavo. International technology transfer policy: from "contract bargaining" to "sourcing". Technovation, v. 19, p. 433-444, $1999 \mathrm{~b}$.

ROSENBERG, Nathan. Perspectives on technology. Cambridge: Cambridge University Press, 1976.

ROSENBERG, Nathan. (1982). Por dentro da caixa preta. Campinas, SP: Editora da Unicamp, 2006.

SABATO, Jorge A. Ensayos de Campera. Buenos Aires: Juarez Editor, 1979.

SABATO, Jorge A. (1975). Empresas y fábricas de tecnología. In: SABATO, J. A. (Ed.). El pensamiento latinoamericano en la problemática ciencia-tecnología desarrollo-dependencia. Buenos Aires: Ediciones Biblioteca Nacional, 2011. p. 309-342.

SANTOS, Ester Carneiro Couto. Fluxos internacionais de tecnologia e a divisão internacional do trabalho: uma abordagem evolucionária. Tese (Doutorado) Universidade Federal de Minas Gerais (UFMG), Belo Horizonte, 2014.

SELL, Susan. Intellectual property and public policy in historical perspective: contestation and settlement. Loyola of Los Angeles Law Review, v. 38, p. 267-321, 2004.

SILVEIRA, Carlos Eduardo Fernandez. Desenvolvimento tecnológico no Brasil: autonomia e dependência num país periférico industrializado. Tese (Doutorado) Campinas, SP, Universidade Estadual de Campinas (Unicamp), 2001.

SIMON, Denis F. International business and the transborder movement of technology: a dialectic perspective. In: AGMON, T.; GLINOW, M. A. V. (Ed.). Technology transfer in international business. New York: Oxford University Press, 1991. p. 5-28.

TIGRE, Paulo Bastos. Paradigmas tecnológicos e teorias econômicas da firma. Revista Brasileira de Inovação,v. 4, n. 1, p. 187-223, 2005.

TIGRE, Paulo Bastos; RIPPER, Mario Dias; ROSELINO, José Eduardo Salles. Tecnologias da Informação e Comunicação (TIC). In: CASSIOLATO, J. E. (Ed.). Perspectivas do investimento na economia do conhecimento. Rio de Janeiro: Synergia, 2010. p. 85-144.

TORRES, E. O mito do sucesso: uma análise da economia japonesa no pós-guerra, 1945-1973. Rio de Janeiro: Instituto de Economia (IE) / Universidade Federal do Rio de Janeiro (UFRJ), 1983. (Texto para Discussão, n. 37). 
UNCTAD. Transfer of technology. UNCTAD Series on issues in international investment agreements, (UNCTAD/ITE/IIT/28). Geneva: United Nations Conference on Trade and Development (UNCTAD/UN), 2001.

VERA-VASSALLO, Alejandro. La inversión extranjera y el desarrollo competitivo en América Latina y el Caribe. Revista de la Cepal, v. 60, p. 129-149, 1996.

VIOTTI, Eduardo B. National learning systems: a new approach on technical change in late industrializing economies and evidences from the cases of Brazil and South Korea. Technological Forecasting \& Social Change, v. 69, p. 653-680, 2002.

WESTPHAL, Larry E.; KIM, Linsu; DAHLMAN, Carl. Reflections on the republic of Korea's acquistion of technological capability. In: ROSENBER, N.; FRISCHTAK, C. (Ed.). International technology transfer: concepts, measures and comparisons. New York: Praeger Publishers, 1985. p. 167-221. 